\title{
A revised analysis of current and emerging Nano suspension technological approaches for cardiovascular medicine
}

\author{
Gayathri Devi Pilli', Karthikeyan Elumalai ${ }^{2,3^{*}}$, Vijey Aanandhi Muthukumar ${ }^{2}$ and Palani Shanmuga Sundaram²
}

\begin{abstract}
Background: This is an objective critique to give an in-depth description of Nano suspensions. This article is attempting to address the issue of whether or not Nano science is realistic with respect to price, with regards to item costs being added to the endeavor and Lipotropic drugs have proven to be rewarding and Lipo-immunotherapy has proven to be beneficial. In modern times, drug marketing and promotion have become crucial to efficient commercializing of successful molecules, pharmaceutical companies often work to increase the chances of promoting successful drugs, these included cardiovascular drugs because of their widespread usage.

Main body: Nano suspension is a Nano metric Colloidal Suspension system i.e., Nano suspensions, in the solid form reaches the bloodstream and Nanoparticle colloids readily available to the target cells. All research on Nanostructures is focused on the four primary dimensions, composition, homogeneity, heterogeneity, elasticity, and agglomeration. Researchers are devising ways to deliver medication and other substances to a damaged cell and diseased region, as well as diagnose the body to pinpoint disease and defects, by way of Nanotechnology.

Short conclusions: The vital analysis of Nano science experiment on Nano suspension is working to achieve the goal of reducing product cost by using Nanotechnology in product development, as it wants to examine the probability of development by utilizing Nanotechnology. The usage of the top-limited technology allows the development of cardiovascular drugs classified under the biopharmaceutical classification system (Class II and Class IV) to use two approaches namely top-down and bottom-up methods.
\end{abstract}

Keywords: Nano suspension, Nanometers, Polymers, Nano beads, Micro emulsions

\section{Background}

The Oral dosage method acknowledges because it is a straightforward approach, feasible measurements, increase profitability, but precise dosing has a greater likelihood of enhancing certain characteristics. The impetus for innovative approaches is stronger as of late, with research pertaining with a greater focus on drug solubility and bioavailability of Nano suspensions, for

\footnotetext{
*Correspondence: karthikeyanelumalai@hotmail.com

2 Department of Pharmaceutical Chemistry and Analysis, School of Pharmaceutical Sciences, Vels Institute of Science, Technology and Advanced Studies, Pallavaram, Chennai 600 117, India

Full list of author information is available at the end of the article
}

example, since its methodologies are novel and various. So, Wettability of new APIs into the market may trigger some difficulties. Controversial approaches that circumventing dissolvability problems include There are many different procedures such as liposomes, micro emulsions, Nano suspension, solid dispersion and particle arrangement that can be used, as well as other different procedures such as co-dissolvability, lipophilic arrangement, and salt development, among others. These methodologies prove not to be valuable in either way with all medications $[1,2]$. Nano suspension is usually has a favorable -results and when compared to a lipid-based dosing [3]. Though the widely used method of Nano-suspension drug preparation is "Top- Down extension", the 
"Bottom-Up" technique could be used to shape a low-dissolvable or a crystalline sort of poorly mobilizable drugs. Amorphous preparation is the most often done utilizing sub-size extension but using the more recently-developed system, which is Nano-suspension an fascinating approach is "Bottom-Up technique, where the particles are reduced to the Nano level, which results in an amorphous suspension. One may reduce the molecular size in a notch by using this Bottom-up technology with low and basic levels of equipment. Thus, stabilization approaches for Nano suspensions should be thoughtfully selected, since they are key factors in their preparation. Sometimes the various polymers and surfactants are used to retain integrity and keep liquids together [4]. It differs from standard suspension in that the particles range in size between 200 and $600 \mathrm{~nm}$. Due to weak solvency and low solubility, lipophilic substances impair bioavailability. It is usually described as how a medication gets to the blood stream. To design formulation and regulatory specifications that are particularly difficult and critical when dealing with poorly water-soluble substances, solubility and accessibility have had to be more closely examined. At the moment, poorly soluble medications account for approximately one-third of all USP (United States
Pharmacopeia) perceived medications. Nanotechnology is defined as innovation on the nanometer scale, which is typically between 0.1 and $100 \mathrm{~nm}$ in size. As with things, "Nanotechnology" is called, means "dwarf and "Nano science" is the analysis of nanos and subatomic things Fig. 1 [5].

\section{Main texts}

\subsection{Development of nano-particle}

A team of chemists in New York City discovered Nano Drugs in the late 1960s, beginning with their discovery as pharmaceutical vehicles first [6]. They imbedded magnetic molecules into Nano-particles by incorporating magnetic nanoparticles into the Nano-fields. Nanometer particles are developed from natural or man-made polymers and range from 0.5 to 500 Nanometers. Molecular materials consisting of ingredients are entrapped, some of which are held together by molecular bonds, some of which are entwined, and then carried into solution. Nanotechnologies are used in the areas of medication formulation, drug delivery, and drug encapsulation, both of which use Nanoparticles, Nanostructures, Nano suspension, Nano spheres, Nano-capsules, Nano- Emulsion and Quantum dots [7].

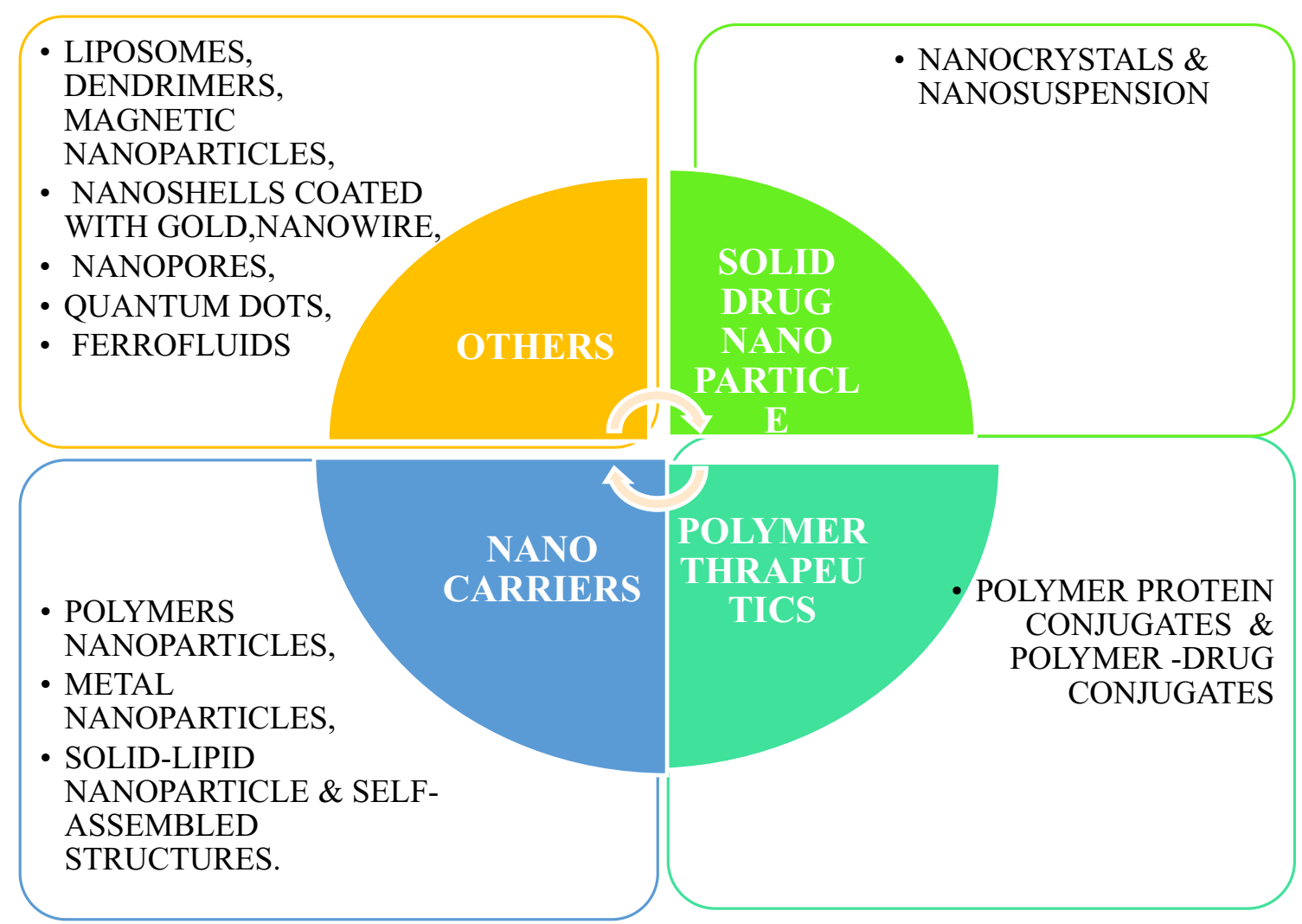

Fig. 1 Different types of nanoparticulate-based drug delivery systems 


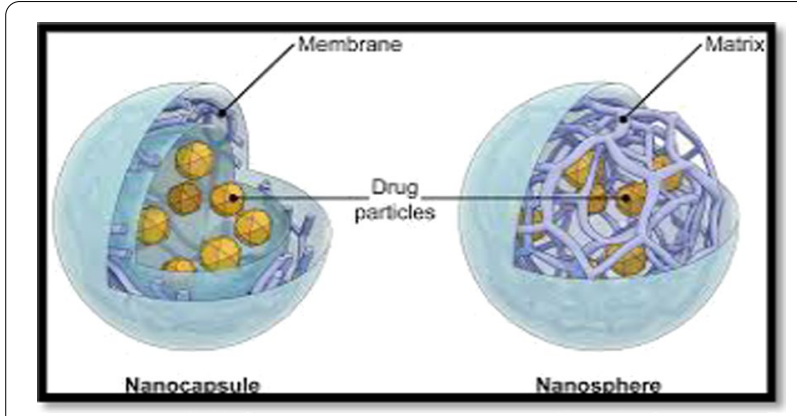

Fig. 2 Schematic representation of nanospheres and nanocapsules [11]

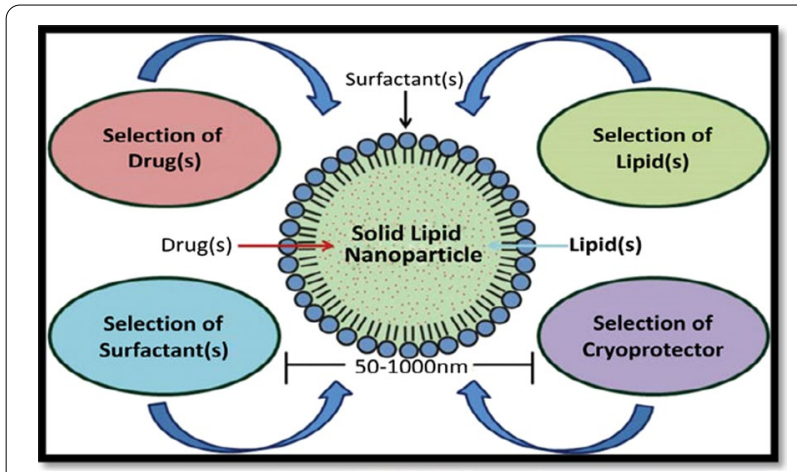

Fig. 3 Schematic representation of solid lipid nanoparticle $[12,13]$

Nanoparticles are colloidal segments with diameters ranging from 1 to $100 \mathrm{~nm}$. They are made up of micro molecular segments in which active segments are broken down, encapsulated, entrapped, adsorbed, or appended. Nano spheres are spheroid rigid, and comprise active ingredients suspended or dissolved inside polymer materials. Nano capsule is designed to contain the drug in the center enclosed by a polymer giving it extra stability. The added value of Nano-capsules and Nanospheres is that they work well with its smaller size and helps simple penetration through vessels and they are suitable for a distribution and targeting can be achieved [8]. The standard diameter of a Solid lipid nanoparticle ranges from 50 to $1000 \mathrm{~nm}$. A sturdy lipid-based nanoparticle can serve as a vehicle for the transport of lipophilic particles. Through addition of surfactants, the lipid profile is adjusted; the emulsifier used depends on the route of administration. Parenteral administrations are particularly restricted [9]. Quantum dots are semi-conductors, which exhibit strongly quantum-mechanical features, but have optical and electronic characteristics that are seemingly distinct from those of other semiconductors. Nanoparticles,

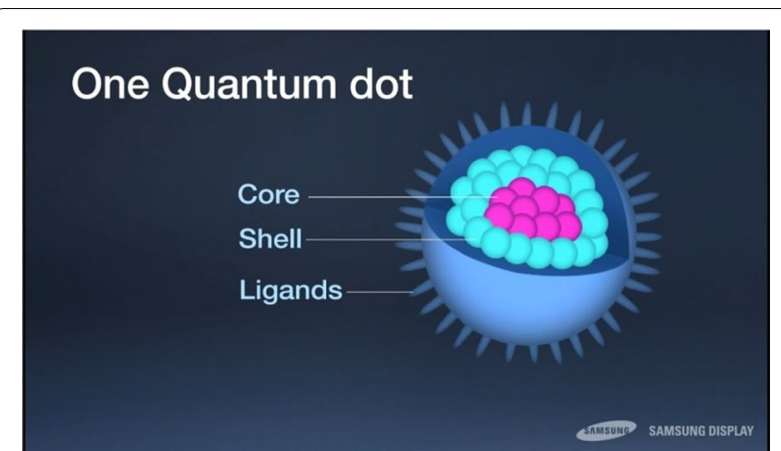

Fig. 4 Schematic representation of quantum dots $[14,15]$

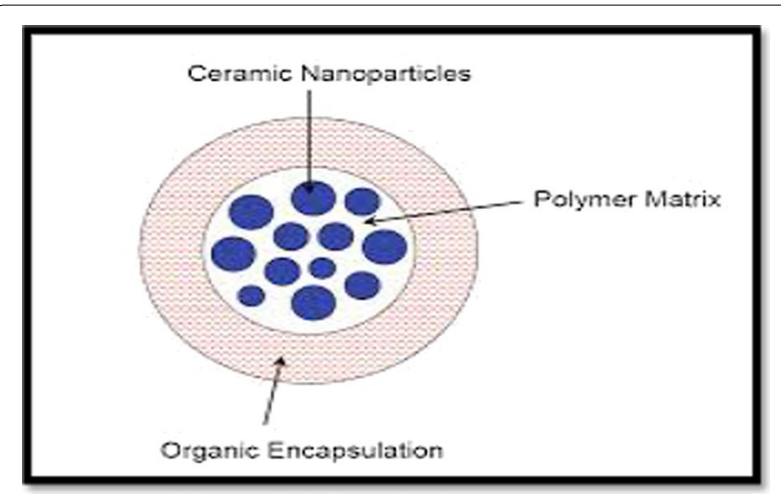

Fig. 5 Schematic representation of ceramic nanoparticles [16]

ranging from 2 to $8 \mathrm{~nm}$ in diameter Fig. 2, 3 and 4 [8-10].

Ceramic Nanoparticles are intertwined biomolecules with a size of less than $50 \mathrm{~nm}$ and are a kind of Nanoparticle made of ceramics, which are inorganic, heat-resistant, non-metallic solids that can be made of both metallic and non-metallic mixtures. Ceramic nanoparticles, including in the field of energy supply and transportation, connectivity, infections, Glaucoma, chemotherapy and most often in medical science, have been used to repress the bone and other conditions Fig. 5 [12].

Liposomes consist of one or more concentrated spheroids of lipophilic bilayers, isolated by natural and human made phospholipids by water or fluid buffer compartment, which are targeted to drug delivery systems. Liposome medicines mitigate systemic toxicity and avoid deterioration at an early stage. Small Uni-lamellar vesicles size 25-100 nm, Large Uni-lamellar vesicles size: larger than 50 Nanometer, Multilamellar vesicles larger than 0.5 nm Fig. 6 [13].

Polypeptides are a kind of Nano forms, which can be made out of both protein and polymers in polymer blends. Many proteins are naturally formed by the 


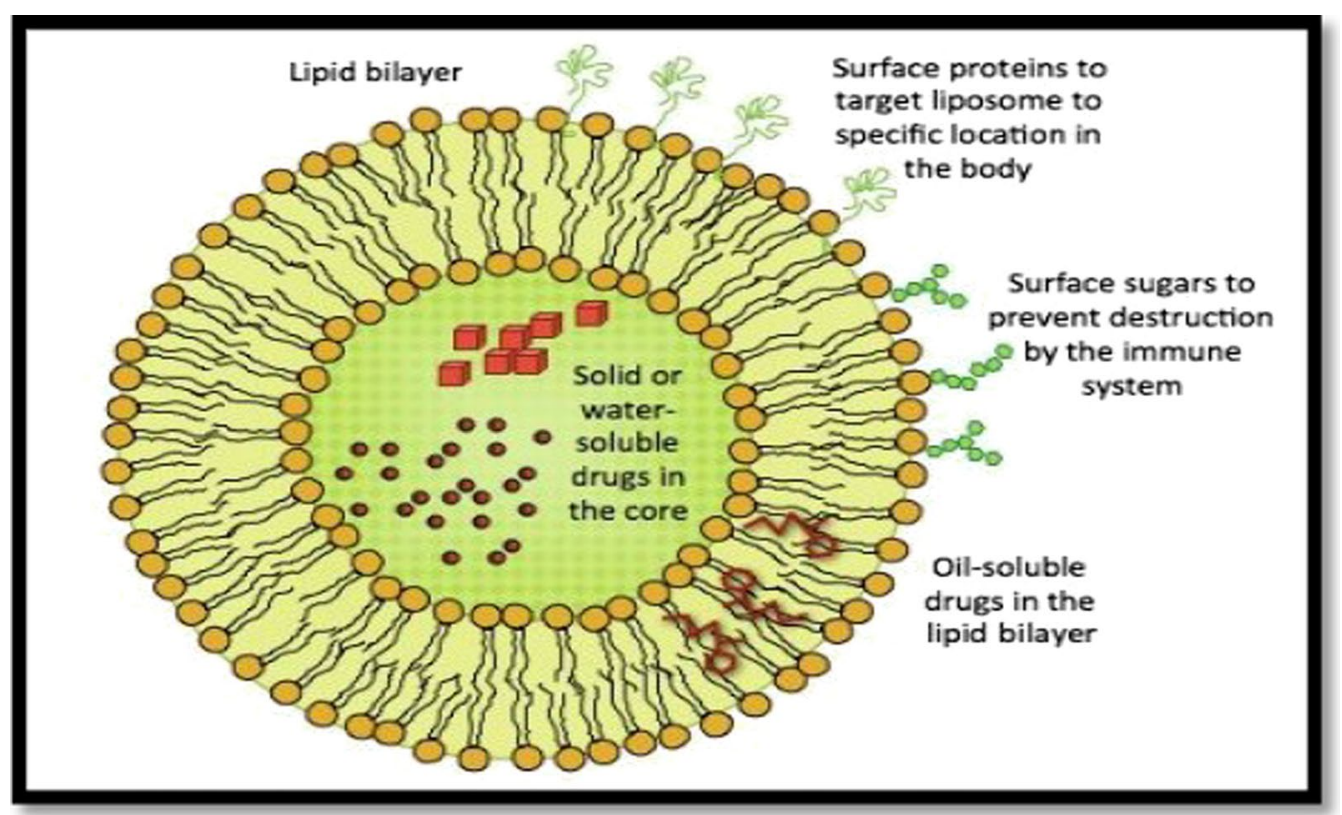

Fig. 6 Schematic representation of liposomes [17]

human body, and they have strong metabolizability, so the protein constituents need to have the advantages of bio-activity and bio-decomposition. While proteins are used as therapeutic medicines, the principal limitations are lack of stability and inadequate circulation inside the body. As of late, they have been researched on for improved pharmacological characteristics, including visualization, bio conjugation, gene delivery, and pharmacological separation. Therapeutic agents can be mixed with polymeric vehicles such as polyethylene glycol to yield a wide distribution, better dispersible drugs, lower immunogenicity, regulated release and enriched protection will offer many benefits for therapy $[14,15]$. Tree-like particles with the characterized cavities are dendrimers, of 1.5 to 10 Nanometers. The dendrimers interact with chemical entities on their surfaces, bind to target molecules, form radio-bioactive, radio-ligands, imaging agents, and acquires aqueous solubility and low toxicity Figs. 7 and 8 [16].

Magnetic Nanoparticles typically have a magnet material, mostly iron, nickel and cobalt, and a valuable synthetic segments. The Magnetic Nano beads, ranging between 50-200 Nanometers [17, 18]. Nan shells claimed to be infrarouge optical activity in relation to gold colloid houses that are made up of a dielectric middle gold sulphide, or silica protected by a stainless steel (iron) sheet, are used in the treatment of carcinomas. Nano-tubes are linear nanostructures made of the 5-10 Nanometer scale of metals, semiconductor or carbon, also single or more layered or adjusted surfaces. A Molecule that has a pore size of 0.3 Nanometers $(\mathrm{nm})$ is a Nano pore, used as a particle singling detector. Ferro fluids are Nano-colloidal fluids consist of small fragments of ferromagnetic or ferrimagnetic particulates trapped in a carrier liquid and coated with surfactants to prevent clumping of each atom. Magnetite, hematite or some other compound comprising iron, or a fluid is composed of Ferro-fluids composed of tiny Nano-size parts (usually $10 \mathrm{~nm}$ or fewer). As ferried are used to create a magnetic reaction, the limited amount needed maintains even distribution of Ferro fluid in the carrier fluid. The Ferro fluid is made up by volume of about $5 \%, 10 \%$ and $85 \%$. The fluid contains desirable solids Fig. 9 [19-30].

Through using Nanostructure and Nano-spaces in specific areas of study, Nanotechnology connects organic and physical sciences; in particular, in Nanomedicine as well as the drug distribution mechanism. Nanomaterials are a molecules between 1 and 100 Nanometers, which affects the periphery of Nano devices from biosensors, microfluidics, drug delivery and microarrays to tissue designs, etc. In nanoscale, Nanotechnology uses technologies to develop Nanomedicine. Targeted drug transport and Controlled drug delivery enhance the studies of kinetics, dynamics, imprecise toxicity, immunogenicity and biologically recognized frameworks that have advanced in their effectiveness [23]. 


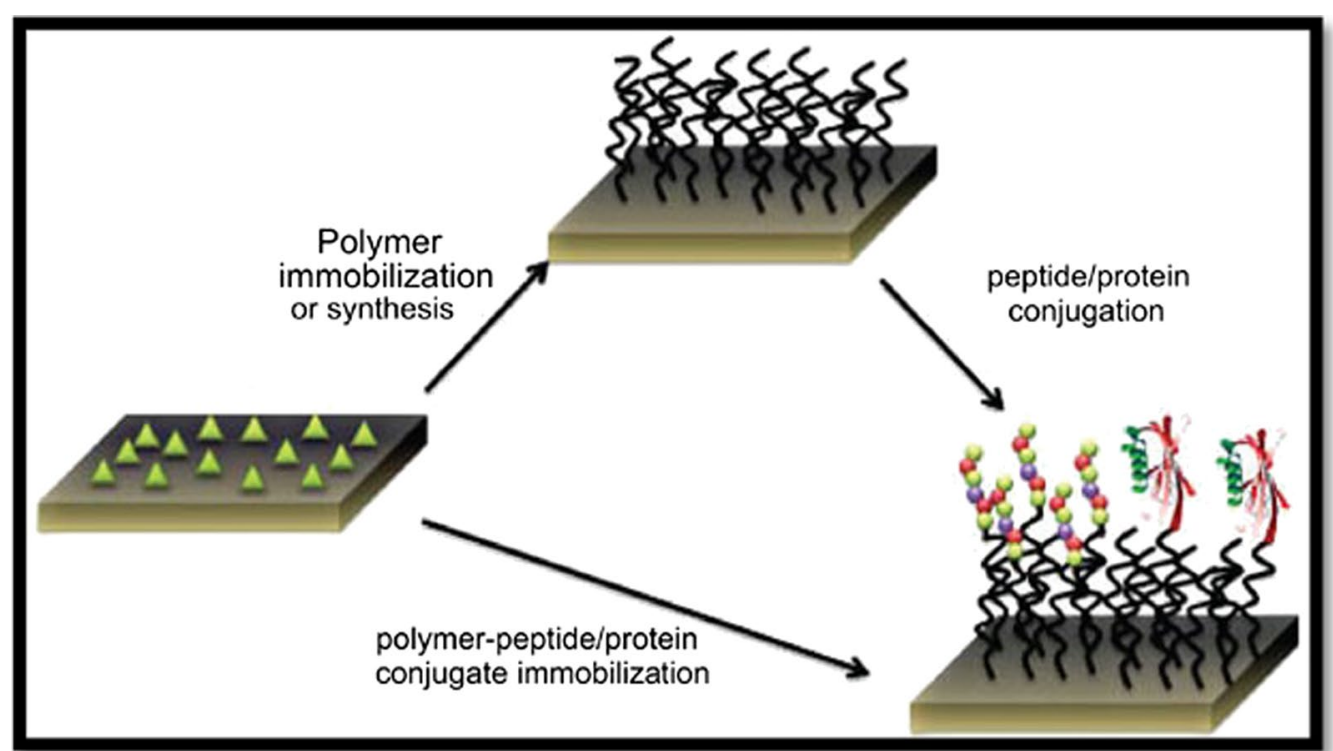

Fig. 7 Schematic representation of polymer protein conjugates [18]

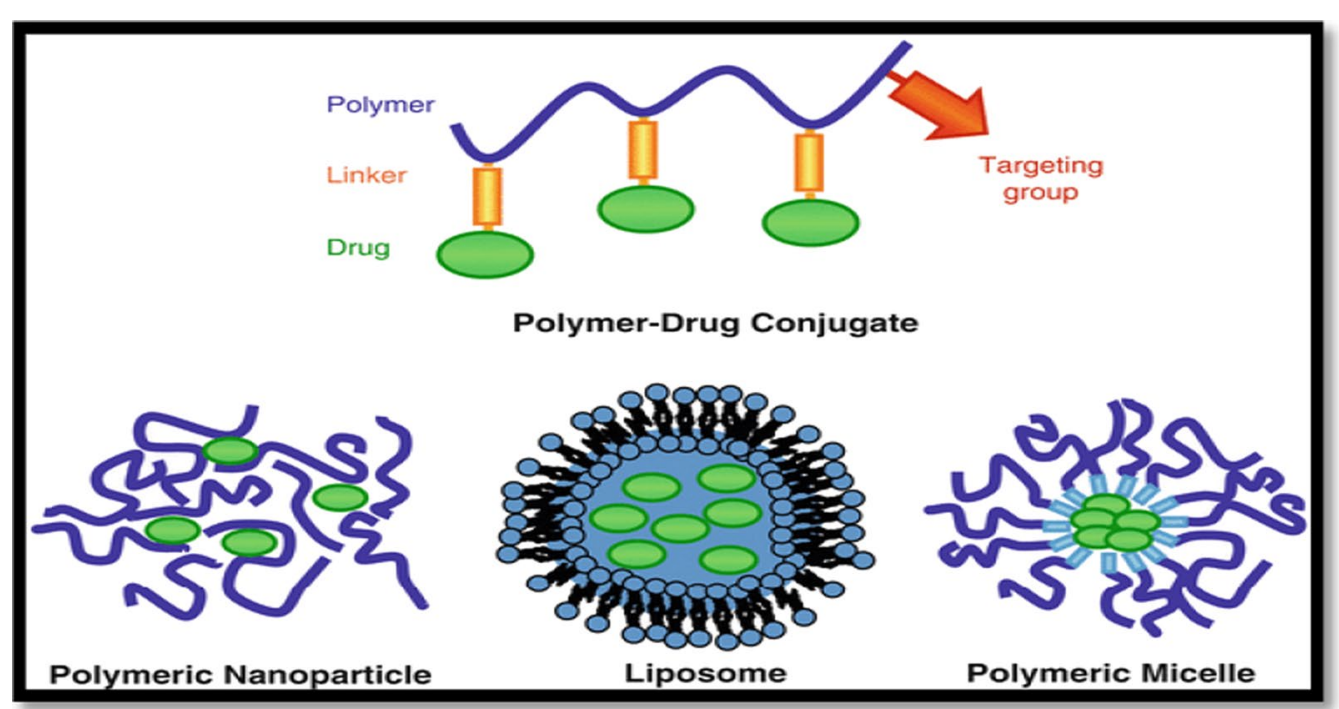

Fig. 8 Schematic representation of polymer drug conjugates $[19,20]$

\subsubsection{Important points for the selection of Nanosuspension medications [31] may be studied}

- Molecules that are poorly dissolved and impenetrable.

- Large atomic weight and dosage.

- Problems with temperature.

\subsubsection{Advantages of nanosuspension}

Nanosuspension seeks to minimize aqueous dissolution, moderate penetration, and limited efficacy in regards to medications used at BCS levels between II and IV Table 1 [24]. 
A Lipid-based Carriers

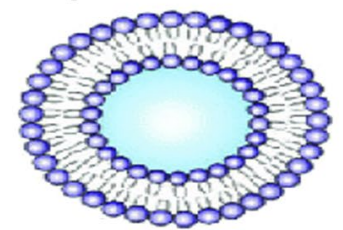

Liposome

B Polymeric Carriers

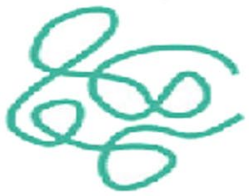

Linear chain

Micelle

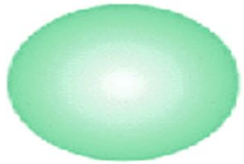

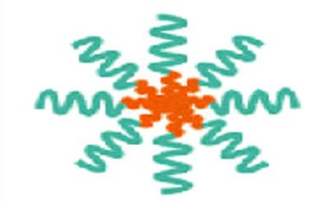

Solid Micro/ Nanoparticle

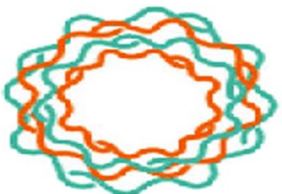

Layer-by-Layer

C Inorganic Carriers

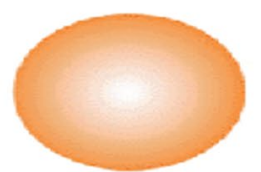

Gold Nanoparticle

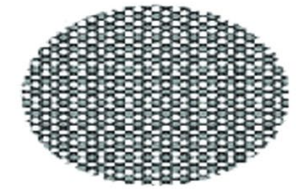

Mesoporous Silica Nanoparticle
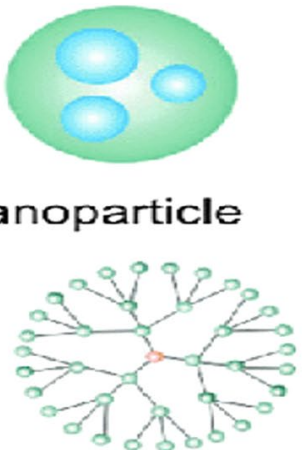

Dendrimer

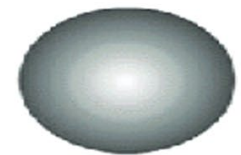

Magnetic Particle

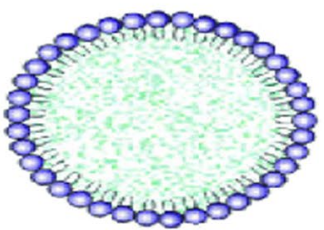

Solid-Lipid Nanoparticle
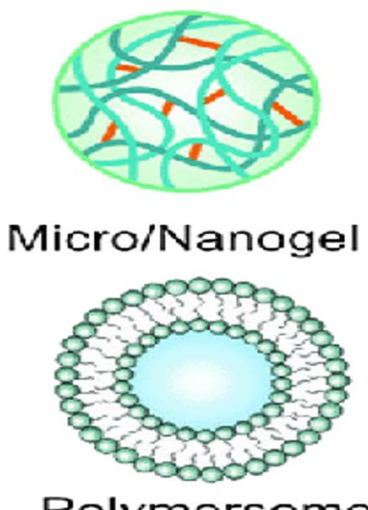

Polymersome

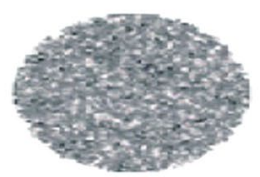

Carbon Spheres

Fig. 9 Schematic representation of nanocarriers [24-30]

Table 1 Advantages of Nano suspension over conventional formulation

\begin{tabular}{lll}
\hline Route of administration & Disadvantages of conventional formulations & Benefits of nanosuspensions \\
\hline Oral & Slow onset of action/poor absorption & $\begin{array}{l}\text { Rapid onset of action/improved solubility so } \\
\text { improved bioavailability }\end{array}$ \\
Ocular & Lachrymal wash off/low bioavailability & Higher bioavailability/dose consistency \\
Intravenous & Poor dissolution/nonspecific action & Rapid dissolution/tissue targeting \\
Intramuscular & Low patient compliance due to pain & Reduced tissue irritation \\
Inhalations & Low bioavailability due to low solubility & Rapid dissolution/high bioavailability/dose regulation \\
\hline
\end{tabular}

a. Nanosuspension should be used with medicines suffering complications in the formulation, as opposed to the lipophilic method.

b. Reduction of particles to nanometer range enhances the solubility and bioavailability of drugs. c. The administration frequency of Nanosuspensions has decreased.

d. Increased physical and chemical stability of Nanosuspension drugs. 
e. The effects are less caused by pharmaceutical excipients in Nanosuspension.

f. Nanosuspension are suitable ophthalmic and nasal providers.

g. Administering parenteral goods intramuscularly or subcutaneously by Nanosuspension their bioavailability enhances with minimal inflammation.

h. The required crystalline particle condition can be obtained in Nanosuspension preparation.

i. Nanosuspension facilitates and is cost-effective for large-scale operation [25-28].

\subsection{Drug overview}

While a number of clinical groups are approved medications using lipid detailing innovations, none are used for the better treatment of disease. Cardiovascular medicines are a most normal medicinal classification and constitute an enticing lipid formulation area of more than 100 FDA products. Because of their small size and low toxicity, nanosuspensions improve drug dispersibility and solubilization.

Nanosuspensions have been shown to improve drug solubility, stability, and bioavailability by means of the research presented in this reviews, So cardiovascular medicines have been recommended in the Nanosuspensions. Table 2 [29].

Prevalence and incidence rates in cardiovascular [30]. The angina pectoris has a reduced flow of blood to the heart and therefore produces chest pain, much like a blockage in the heart. The Arrhythmia, a sporadic heart beat or a cardiac band, or a pulse that is too low 60 beats per minute, bradycardia or tachycardia, a rhythm which is too high 100 beats per minute, is known as excessive heart beating. Congenital coronary heart disease is a problem with the heart's ability and shape that occurs at birth and affects the heart muscle. The Cardiac attack occurs due to blockages in the supply of blood through the heart muscle as blood clots build in the arteries. A Cardiac failure arose owing to a progressive disease of pumping inability of the heart. Cardiomyopathy is a disorder in which a heart contraction finds it more difficult to transfer blood to the remainder of the body. The following are the different forms of cardiomyopathy. Hypertrophic cardiomyopathy occurs as a consequence of a blockage at one part of the heart for no apparent reason. Dilated cardiomyopathy is triggered by an artery blockage. Restrictive cardiomyopathy is caused by ventricle rigidity. The effect of elevated tension is broken heart syndrome [23-27]. Mitral reverse flux results from the reverse flux of the blood from the ventricle to the atrium and may also occur from the atrium to the lungs, leading to respiratory problems and straining the hearts muscles leads to arrhythmia. Atrial fibrillation is a form of erratic pulse with a fast heart rhythm that may lead to more serious heart complications. Rheumatic disease results from rheumatic fever that damages connective tissue, especially damaging heart valves. An Aneurysm is a condition in which a mass forms in an artery. The disease of arteriosclerosis involves cholesterol or other compounds plunging through and into the artery. In Raynaud's disease, arteries temporarily block blood supply, such as in cold weather, causing numbness in certain areas of the body. An ischemic stroke occurs as blood clots in a blood vessel in the brain. Buerger's disease is a rare infection that can trigger gangrene in the arteries and veins of the arms and legs [28-30].

\subsection{Tremendency for nanosuspension \\ 2.3.1 Bottom-up}

Bottom-up Approach and Top-down Process are two methods for organizing Nanosuspension. In terms of planning, the bottom-up scale-up process employs the Precipitation methodology. The particles are acquired in an amorphous form in this method, which is from the atom stage to the solid object, by using techniques such as anti-solvent or temperature changes, or both depending on the necessity. This method produces particles dissolved in miscible anti-solvent and crystals; the only drawback is that the substance must be dissolved in more than one solvent [32-36].

\subsubsection{Top-down}

There are two forms of Top-Down strategies: Media Milling and High-Pressure Homogenization. Dry milling and Media milling: The Nanosuspension is prepared in this method by using a high-pressure mill to shorten particle weight. This mills are made up of tiny milling balls/ spherical rotators, and the fluid drug is moved into this milling region at high pressure and controlled temperature, and the particle size is decreased due to centrifugal forces inside the mill. Glass, zirconium oxide, or massively cross-linked polystyrene resin was used to make the spherical rotators. For medications that are difficult to dissolve, Nanosuspension employs a dry grinding process. Polyvinylpyrrolidone (PVP), Polyethylene glycol (PEG), Hydroxypropyl methylcellulose (HPMC), and Cyclodextrin subsidiaries are among the dissolvable polymers and co-polymers used. Dry granulating is often cost-effective and can be performed without the use of organic solvents. It is the most widely used for the preparation of Nanosuspension of certain ineffectively waterinsoluble drugs [37-39]. 
Table 2 Cardiovascular Drugs under BCS classification

\begin{tabular}{|c|c|c|c|c|}
\hline S. no & Cardiovascular agents & BCS class $(C \log P)$ & BCS class $(\log P)$ & $\begin{array}{l}\text { Solubility/ } \\
\text { permeability }\end{array}$ \\
\hline \multirow[t]{11}{*}{1} & ACE inhibitors & & & \\
\hline & (a) Benazepril & Class 1 & Class 1 & High/high \\
\hline & (b) Captopril & Class 3 & Class 3 & High/low \\
\hline & (c) Cilazapril & Class 3 & Class 3 & High/low \\
\hline & (d) Enalapril & Class 1 & Class 1 & High/high \\
\hline & (e) Imidapril & Class 1 & Class 3 & High/low \\
\hline & (f) Lisinopril & Class 3 & Class 3 & High/low \\
\hline & (g) Perindopril & Class 3 & Class 1 & High/low \\
\hline & (h) Quinapril & Class 1 & Class 1 & High/high \\
\hline & (i) Ramipril & Class 1 & Class 1 & High/high \\
\hline & (j) Temocapril & Class 1 & Class 1 & High/high \\
\hline \multirow[t]{7}{*}{2} & Angiotensin II receptor antagonists & & & \\
\hline & (a) Candesartan cilexetil & Class 2 & Class 2 & Low/high \\
\hline & (b) Eprosartan & Class 2 & Class 2 & Low/high \\
\hline & (c) Irbesartan & Class 2 & Class 2 & Low/high \\
\hline & (d) Losartan & Class 3 & Class 3 & High/low \\
\hline & (e) Telmisartan & Class 2 & Class 2 & Low/high \\
\hline & (f) Valsartan & Class 2 & Class 2 & Low/high \\
\hline \multirow[t]{6}{*}{3} & Antiadrenergic agents & & & \\
\hline & (a) Carvedilol & Class 2 & Class 2 & Low/high \\
\hline & (b) Clonidine & Class 3 & Class 3 & High/low \\
\hline & (c) Doxazosin & Class 1 & Class 1 & High/high \\
\hline & (d) Reserpine & Class 1 & Class 1 & High/high \\
\hline & (e) Terazosin & Class 1 & Class 3 & High/low \\
\hline \multirow[t]{3}{*}{4} & Antiarrhythmics & & & \\
\hline & (a) Mexiletine & Class 1 & Class 1 & High/high \\
\hline & (b) Pilsicainide & Class1 & Class1 & High/high \\
\hline \multirow[t]{8}{*}{5} & Antiplatelet Agents & & & \\
\hline & (a) Cilostazol & Class 2 & Class 2 & Low/high \\
\hline & (b) Clopidogrel & Class 2 & Class2 & Low/high \\
\hline & (c) Ethyl icosapentate & Class 2 & Class2 & Low/high \\
\hline & (d) Sarpogrelate hydrochloride & Class 1 & Class1 & High/high \\
\hline & (e) Ticlopidine & Class 2 & Class2 & Low/high \\
\hline & (f) Triflusal & Class 2 & Class2 & Low/high \\
\hline & (g) Warfarin & Class 2 & Class2 & Low/high \\
\hline \multirow[t]{4}{*}{6} & Antihyperlipidemics & & & \\
\hline & (a) Ezetimibe & Class 2 & Class 2 & Low/high \\
\hline & (b) Fenofibrate & Class 2 & Class 2 & Low/high \\
\hline & (c) Niacin & Class 3 & Class 3 & High/low \\
\hline \multirow[t]{6}{*}{7} & Beta-Adrenergic & & & \\
\hline & Blocking Agents & & & \\
\hline & (a) Atenolol & Class 3 & Class 3 & High/low \\
\hline & (b) Bisoprolol & Class 1 & Class 3 & High/low \\
\hline & (c) Metoprolol & Class 1 & Class 1 & High/high \\
\hline & (d) Propranolol & Class 1 & Class 1 & High/high \\
\hline \multirow[t]{4}{*}{8} & Calcium Channel Antagonists & & & \\
\hline & (a) Amlodipine & Class 1 & Class 1 & High/high \\
\hline & (b) Benidipine & Class 2 & Class 2 & Low/high \\
\hline & (c) Cilnidipine & - & - & —/high \\
\hline
\end{tabular}


Table 2 (continued)

\begin{tabular}{|c|c|c|c|c|}
\hline S. no & Cardiovascular agents & BCS class $(C \log P)$ & BCS class $(\log P)$ & $\begin{array}{l}\text { Solubility/ } \\
\text { permeability }\end{array}$ \\
\hline & (d) Diltiazen & Class 1 & Class 1 & High/high \\
\hline & (e) Lercsnidipine & - & - & --/high \\
\hline & (f) Manidipine & Class 2 & & Low/high \\
\hline & (g) Nicardipine & Class 1 & Class 1 & High/high \\
\hline & (h) Nifedipine & Class 2 & Class 2 & Low/high \\
\hline & (i) Nilvadipine & Class 2 & - & Low/high \\
\hline & (j) Verapamil & Class 2 & Class 2 & Low/high \\
\hline \multirow[t]{3}{*}{9} & Cardiovascular Agents & Class 3 & Class 3 & High/low \\
\hline & (a) Digoxin & & & \\
\hline & (b) Methyldopa & Class 3 & Class 3 & High/low \\
\hline \multirow[t]{7}{*}{10} & Diuretics & & & \\
\hline & (a) Acetazolamide & Class 4 & Class 4 & Low/low \\
\hline & (b) Amiloride & Class 3 & Class 3 & High/low \\
\hline & (c) Furosemide & Class 4 & Class 4 & Low/low \\
\hline & (d) Hydrochlorothiazide & Class 4 & Class 4 & Low/low \\
\hline & (e)Indapamide & Class 1 & Class 1 & High/high \\
\hline & (e) Spironolactone & Class 2 & Class 2 & Low/high \\
\hline \multirow[t]{6}{*}{11} & HMG-CoA Reductase Inhibitors & Class 2 & Class 2 & Low/high \\
\hline & (a) Atorvastatin & & & \\
\hline & (b) Fluvastatin & Class 1 & Class1 & High/high \\
\hline & (c) Lovastatin & Class 2 & Class 2 & Low/high \\
\hline & (d) Parvastatin & Class 1 & Class 3 & High/low \\
\hline & (e) Simvastatin & Class 2 & Class 2 & Low/high \\
\hline \multirow[t]{8}{*}{12} & Vasodilators & & & \\
\hline & (a) Beraprost & Class 1 & Class 1 & High/high \\
\hline & (b) Hydralazine & Class 3 & Class 3 & High/low \\
\hline & (c) Isosorbide dinitrate & Class 3 & Class 3 & High/low \\
\hline & (d) Limaprost & Class 1 & Class1 & High/high \\
\hline & (e) Nicorandil & Class 3 & - & High/low \\
\hline & (f) Nitroglycerin & Class 1 & Class 3 & High/low \\
\hline & (g) Trimetazidine & Class 3 & Class 3 & High/low \\
\hline
\end{tabular}

\subsubsection{High-pressure homogenization}

The particle size is limited in the high-pressure homogenization method by going through a small size pore at high pressure. The technique is based on the cavitation forces of drug particles in the fluid level. These forces are powerful enough to convert the drug from micro atoms to Nano atoms [40-42].

It is classified into two types such as,

a. Disso Cubes (Homogenization in water media)

b. Nano-Edge \& Nano-Jet (Homogenization in lipophilic media)

\subsubsection{Disso-cubes}

In the piston-gap, homogenizing reduction in size relies on cavitation rules. Disso-Cubing was engineered to be homogenizing for piston-gap environments. Particles are being diminished by force and even by particle bombardment [43-46]. A thin void of $25 \mu \mathrm{m}$ is abruptly filled by scattering in a chamber of $3 \mathrm{~cm}$ in diameter. The determining variable of the device is cavitation in the DissoCubes. The stream through a chamber is very steady under the law of Bernoulli. The drop in diameter from $3 \mathrm{~cm}$ to $25 \mu \mathrm{m}$ raises dynamic pressure and reduces the static pressure below the water-water breakdown limit. Drug Nanocrystals are mostly based on variables such as temperature, no homogenization cycles and strain of homogenization. However, the drop in static pressure is not necessary for cavitation instead of water, oils or an 
oily boiling point to be homogenized to decrease the particle size and milling operation. The acquired results have been close to Disso-Cubes and thus should be used in milder conditions for thermo labile compounds [47-49].

\subsubsection{Nanoedge}

In Nanoedge technology, medication particles are dissolved in solvents that are dissolved and mixed with a precipitated anti-solvent and homogenized to limit the growth of crystals. The downside of this approach is that it can be corrected by the homogenization of long-term equilibrium. The mixture of precipitation, homogenization and evaporation is thus the Nanoedge and these approaches combine to produce smaller particle sizes and improved stability [50].

\subsubsection{Nano jet}

The technology uses a closed unit, which splits the Nanosuspension flow into segments and bombards each other at high pressure, which reduces the size of the particle due to this process. During this procedure, the strong shear pressure causes a reduction in particle size. M110L and M110S micro fluidizers are the instruments used in this Nano-jet. The main obstacle to this approach is the fluidizer that the element comprises smaller particles in a bigger division [51].

\subsubsection{Solvent-evaporation technique}

A drug is combined with the polymer solvent and the surfactant containing mixture is dissolved by the water. To precipitate the particles, an evaporation process is required. By going via high-pressure stirrers, crystal growth and production may be slowed [52].

\subsubsection{Precipitation technique}

The most well-known precipitation method is the antisolvent procedure under which the compound is disintegrated into a solvent, which is organically dissolved and mixed with a miscible anti-solvent. The shapes of blending vary significantly [53-55].

\subsubsection{Supercritical-fluid process}

A supercritical fluid (SF) is commonly described as a liquid with a critical temperature (Tc) and considerable pressure (Tp). Nanosuspension is prepared using two processes: a rapid expansion of supercritical solution phase (RESS) and a supercritical anti-solvent process, followed by precipitation of the compressed anti-solvent process (PCA). As the solvent dries, the ions supersaturates and precipitate as fine crystals. The supercritical anti-solvent treatment employs a supercritical liquid in which a substance is ineffectively soluble, as well as a drug solvent that is often miscible with the supercritical liquid [56]. The disadvantages of the aforementioned techniques include the use of hazardous solvents, elevated levels of surfactants as opposed to other processes, and particle crystallization due to high super-saturation, which can result in undesirable polymorph [57-59].

\subsection{Patents filed: nanotechnology patents Of 2018 at the USPO \& EPO statistics}

According to 2019 studies, the share of nanotechnology patents in total patents filed at two patent offices was relatively 2.5 percent to 3 percent, despite a slight increase in recent years. These statistics suggest that a significant proportion of scientific achievements in the fields of nanotechnology still remains at the level of scientific article publication [60].

\subsection{Applications}

\subsubsection{Intravenous administration}

The intravenous management route offers fast, quick, increased bioavailability and prevents metabolism at first passes. It is the preferred path for medicines not consumed or decayed in the GIT. Nanosuspension increases clinical efficiency and reduces cost-effectiveness by improving dosage proficiency and reduced infusion sizes.

\subsubsection{Bio-accumulation improvement}

The drug's low oral use rate is attributed to weak dissolvability, penetration, or durability inside the GIT. Nanosuspension addresses the issue of poor bioactivity by addressing the issues of weak dissolvability and weak membrane penetration. Higher bioavailability and longterm physical stability of Nanosuspension can improve therapeutic results. The drug's dissolvability improves as the surface area of the drug particles increases from micrometer to nanometer scale. The Nanosuspension increases disintegration of lyophilized Nanosuspension material in (90 percent in $20 \mathrm{~min}$ ) association with rough powder disintegration in (15 percent in $20 \mathrm{~min}$ ).

\subsubsection{Pulmonary administration}

Nanosuspension are electronic or ultrasonic nebulizers used for pulmonary medication distribution. Because of their Nano scale and the adhesives used in Nanosuspension, they have higher selectivity, less drug loss, and a longer residence period at the target point. Pulmonary Nanosuspension increase medication diffusion and disintegration, which improves bioaccumulation and predicts unintended drug deposition in the mouth and pharynx.

\subsubsection{Ocular administration}

Ocular drug delivery as a Nanosuspension has been concentrated to provide a gentle and long-lasting 
release of the prescription. For viable treatments, the incorporation of bio-degradable polymer induces delayed residual period in the eye sac. Drug Nanoparticle adhesives have been shown to reduce drug degradation.

\subsubsection{Drug targeting}

Nanosuspension may also be used for a targeted drug delivery mechanism by concentrating on the particle surface region, and adjusting the stabilizer can effectively change the in vivo behavior. The medications are soaked up by the phagocytic cell, allowing for drug targeting.

\subsubsection{Mucoadhesive nanosuspension}

As the suspension diffuses through the fluid media and rapidly reaches the mucosal surface, the Nanosuspension is controlled. Nanosuspension bind to the intestinal surface through "bio-adhesion," and the repository procedure begins immediately. The Nanosuspension adhesiveness aids in enhancing bioavailability while still adhering to the Noyes-Whitney state.

\section{Conclusions}

One of the main challenges is achieving a goal in finding an appropriate nanosuspension preparation approach with low energy input and erosion contamination, such as the bottom-up method and top-down method. This review dwells upon both top-down and bottomup technologies for nanosuspension preparation. The characters and advantages of drug nanosuspension, corresponding to the characterization techniques, solidification methods, and drug delivery dosage forms, were discussed in detail. We conclude that the drugs which are belonging to the BCS CLASS II and IV were most eligible to prepare in the form of Nanosuspension so that solubility problems can be overcome and ultimately bioavailability also increase suspensions were also made. Higher bioavailability and long-term physical stability of Nanosuspension can improve therapeutic results. Nanosuspension increases clinical efficiency and reduces cost-effectiveness by improving dosage proficiency and reduced infusion sizes.

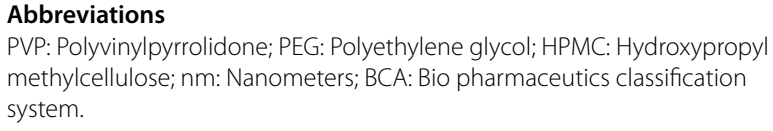

Acknowledgements

Not applicable.

\section{Authors' contributions}

GDP: Collected Literature. KE: Designed the work. VAM: Prepared the Manuscript. PSS: Done the Language Edition. All authors have read and approved the manuscript.

\section{Funding}

Not applicable.

\section{Availability of data and materials Not applicable.}

\section{Declarations}

Ethics approval and consent to participate Not applicable.

\section{Consent for publication}

Not applicable.

\section{Competing interest \\ The authors declare no competing interest in this study.}

\section{Author details}

${ }^{1}$ Department of Pharmaceutics, School of Pharmaceutical Sciences, Vels Institute of Science, Technology and Advanced Studies, Pallavaram, Chennai 600 117, India. ${ }^{2}$ Department of Pharmaceutical Chemistry and Analysis, School of Pharmaceutical Sciences, Vels Institute of Science, Technology and Advanced Studies, Pallavaram, Chennai 600 117, India. ${ }^{3}$ Faculty of Pharmacy, Bharath Institute of Higher Education and Research, Selaiyur, Chennai 600 073, India.

Received: 26 July 2021 Accepted: 4 January 2022

Published online: 15 January 2022

\section{References}

1. Roya Y, Krasimir V, Spomenka S (2015) Nanosuspension technologies for delivery of poorly soluble drugs. J Nanomater 2015:1-13

2. Jayanta KP, Gitishree D, Leonardo FF, Estefania VRC, Maria PRT et al (2018) Nano based drug delivery system: recent developments and future prospects. J Nanobiotechnol 71:1-33

3. Smita SA, Sagar TM, Saudagar RB (2017) Review article Nanosuspension an overview. Int J Curr Pharm Res 9:19-23

4. Sachin SP, Bajirao RD, Sandip PN, Rajan SS (2017) Nanosuspension technologies for delivery of drugs. Nano Nanotechnol Res 4(2):59-66

5. Chaudhari SP, Kamble SC, Mahajan RA, Jagdale S, Ratnaparkhi MP (2010) Nanosuspension: a novel drug delivery system. J Pharm Res 3(2):241-246

6. Mitesh P, Arpit S, Patel NM, Patel MR, Patel KR (2011) Nanosuspension: a recent approach for nano drug delivery system. In J Curr Pharm Rev Res 3(4):96-101

7. Diana S, Debora F, Joana LR, Lígia RR (2017) Nanotechnology: a revolution in targeted drug delivery. Int J Bas Clin Pharm 6(12):2766-2773

8. Girish BS, Rakesh PP, Prajapati BG, Nikunjana AP (2011) Solid lipid nanoparticles and nano lipid carriers: as novel solid lipid based drug carrier. Int Res Pharm 2(2):40-52

9. Mukerjee S, Ray S, Thakur RS (2009) Solid lipid nanoparticles: a modern formulation approach in drug delivery system. Int J Pharm Sci 71(4):349-358

10. Menaka J (2018) Current trends in industrial scale synthesis of quantum dots and its application in electronics. In Handbook of nanomaterials for industrial applications, pp 381-385

11. Suffredini G, East JE, Levy LM (2013) Studied a new applications of nanotechnology for neuroimaging citied in March 2013. Am J Neuroradiol 35:7. https://doi.org/10.3174/ajnr.A3543

12. Aura IMV, Teresa GQ, Rosa ENA, Laura-SAT VC (2012) Polymeric and ceramic nanoparticles in biomedical applications. J Nano Technol 2012:1-10 
13. Asif ISF, Jasjeet KS, Sanjula B, Shweta D, Javed A (2012) Nanostructured lipid carriers system: recent advances in drug delivery. J Drug Target 20:813-830

14. Iriny E, Colson Y, Grinstaff M (2019) Polymer-drug conjugate therapeutics: advances, insights and prospects uses. Nat Rev Drug Dis Rev 18:273-294

15. Monika LG, Priyanka GP, Pradum PI (2020) Polymer-drug conjugates as nanomedicine: a review. Int J Poly Mater Poly Biol 69:990-1014

16. Ardhendu KM (2021) Dendrimers in targeted drug delivery applications: a review of diseases and cancer. Int J Poly Matrt Poly Biol 70(4):287-297

17. Kai W, Diqing S, Jinming L, Renata S, Wang JP (2019) Magnetic nanoparticles in nanomedicine: a review of recent advances. Nanotechnology 30(50):502003

18. Ting $G$, Junxing $H$, Chenglin $Z$, Weizhong $T$, Hong $Y$, Xingmao J, Jun $Y$, Yujuan S, Yanhong X, Xuefeng B, Xiaoqian F (2018) The recent advances of magnetic nanoparticles in medicine. J Nanotechnol 2018:1-8

19. Gul R, Zainab N, Asad M, Salma B, Anwar HAS, Shabeer AM, Ghulam A (2019) An overview of the recent progress in the synthesis and applications of carbon nanotubes. J of Car Res 5(1):1-31

20. Yong W, Dali Z, Qiulin T, Michal XW, Li-Qun G (2011) Nanopore-based detection of circulating microRNAs in lung cancer patients. Int Nat Nanotechnol 6:668-674

21. Azadeh S, Hashemi ASMGJMM (2020) Laser-assisted cancer treatment, in bio-engineering approaches to cancer diagnosis and treatment. Sci Direct 6:131-156

22. Dubrovskiy AA, Balaev DA, Shaykhutdinov KA, Bayukov OA, Pletnev ON, Yakushkin SS, Bukhtiyarova GA, Martyanov ON (2015) Size effects in the magnetic properties of e- $\mathrm{Fe}_{2} \mathrm{O}_{3}$ nanoparticles. J Appl Phys 118:213901-213917

23. Patel AP, Patel JK, Patel K, Deshmukh AB, Mishra BR (2011) A review on drug nanocrystals a carrier free drug delivery. Int J Res Ayurveda Pharm 2(2):448-458

24. Boubbou KE (2018) Magnetic iron oxide nanoparticles as drug carriers: clinical relevance. Nanomedicine 13:953-971

25. Sarabjeet SS, Hicham F, Baljit S (2007) Nanotechnology-based drug delivery systems. J Occup Med Toxicol 2:16

26. Sneha D, Srinivas B, Rajashree H (2018) Preparation and characterization of oral nanosuspension loaded with curcumin. Int J Pharm Sci 10(6):90-95

27. Patravale VB, Abhijit AD, Kulkarni RM (2004) Nanosuspension: a promising drug delivery strategy. J Pharm Pharmacol 56(7):827-840

28. Sachin SP, Bajirao RD, Sandip PN, Rajan SS (2017) Nanosuspension technology in drug delivery system. Nanosci Nanotechnol Res 4(2):59-66

29. Md. Saddam Hussain, Abdul Baquee Ahmed And Jiban Debnath (2020) Nanosuspension: A Promising Drug Delivery System For Poorly Water Soluble Drug And Enhanced Bioavailability. IJSPR (2020), Volume 11, Issue 10

30. Zhao H, Li R (2008) Effect of water absorption on the mechanical and dielectric properties of nano-alumina filled epoxy nanocomposites, composites Part A. Appl Sci Manuf 39:602-611

31. Lakshmi P, Kumar GA (2010) Studied a nanosuspension technology: a review citied in september 2010. Int J Pharm Pharmaceut Sci 2(4):3540

32. Venkatesha T, Rajesh C, Sekar M, Jeevanandham S, Reza KH, Nagi Reddy BKV (2011) Nanosuspension: ideal approach for the drug delivery of poorly water soluble drugs. Der Pharm Let 3(2):203-213

33. Stanekzai A, Vikrant SCK, Pankaj K (2019) Nanosuspension as a promising approach to enhance bioavailability of poorly soluble drugs: an update. J Drug Deliv Therap 9(2):574-582

34. Chowdary KPR, Madhavi BLR (2005) Novel drug delivery technologies for insoluble drugs. Ind Drug 42(9):557-563

35. Cornelia MK, Rainer H (2006) Drug nanocrystals of poorly soluble drugs produced high-pressure homogenizations. Eur J Pharm Biol 62(1):3-16

36. Krause KP, Kayser O, Mader K, Gust R, Muller RH (2000) Heavy metal intamination of nanosuspensions produced by highpressure homogenizations. Int J Pharm 196(2):169-172

37. Elaine MML, Gary GL (2008) Drug nanoparticles: formulating poorly water-soluble compounds. Toxicol Pathol 6(1):43-48

38. Desmond H, Keiko O, David JC, Chan HK, Raper JA, Ye L, Yun J (2010) Pure drug nanoparticles in tablets: what are the dissolution limitations. J Nan Res 12:1743-1754
39. Jain D, Khatri C, Rani A (2010) Fly ash supported calcium oxide as recyclable solid base catalyst for Knoevenagel condensation reaction. Fu Process Technol 91:1015-1021

40. Irene P, Ruggero B, Ferdinando G (2006) Solid-state chemistry and particle engineering with supercritical fluids in pharmaceutics. Eur J Pharm Sci 27:299-310

41. Arun KN, Deecaraman M, Rani C, Mohanraj KP (2009) Preparation and solid state characterization of atorvastatin nanosuspensions for enhanced solubility and dissolution. Int J Pharm Technol Res 1:1725-1730

42. Chauhan NN, Niraj VP, Suthar SJ, Jayvadan KP, Manish PP (2012) Micronization of BCS class-II drugs by various approaches for solubility enhancement-a review. Res J Pharm Technol 5(8):999-1005

43. Li W, Yang Y, Tian Y, Xu X, Chen Y (2011) Preparation and in vitro/in vivo evaluation of revaprazan hydrochloride nanosuspension. Int J Pharm 408:157-162

44. Jorvekar P, Pathak AA, Chaudhari PD (2012) Formulation development of aceclofenac loaded nanosuspension by three square (32) factorial design. Int J Pharm Sci Nanotechnol 4:1575-1582

45. Banavath H, Sivarama RK, Tahir A, Sajid A, Pattnaik G (2011) Nanosuspension: an approach to enhance solubility of drugs. Int J Pharm Sci Res 2(2):81-87

46. Shegokar R, Müller RH (2010) Nanocrystals: industrially feasible multifunctional formulation technology for poorly soluble actives. Int J Pharm 399:129-139

47. Srilatha K, Prabhavathi DB, Lingaiah N, Prasad R, Sai PP (2012) Bio-diesel production from used cooking oil by two-step heterogeneous catalyzed process. Bio Technol 119:306-311

48. Prasanna L, Kumar G (2010) Nanosuspension technology: a review. Int J Pharm Pharm Sci 2(4):35-40

49. Xiaohui $P$, Jin S, Mo L, Zhonggui H (2009) Formulation of nanosuspensions as a new approach for the delivery of poorly soluble drugs. Curr Nano 5:417-427

50. Mohanty S, Boga PK (2009) Role of nanoparticles in drug delivery system. Int J Res Pharm Biomed Sci 1(2):41-66

51. Ashaben P, Kishore C, Vibhuti A, Ashim KM (2013) Ocular drug delivery systems: an overview. World J Pharmacol 2(2):47-64

52. Ensign LM, Cone R (2012) Nanosuspensions: potent vehicles for drug delivery and bioavailability enhancement of lipophilic drugs. J Pharm Res 5(3):1548-1554

53. Gupta A, Goyal S (2012) Nanosuspension—a novel approaches. Drug Deliv Syst 12(1):50-64

54. Prabhakar C, Bala KK (2011) A review on nanosuspensions in drug delivery. Int J Pharm Biol Sci 2:549-558

55. Sainia A, Jata S, Shekhawat D, Kumar A, Dhayala V, Agarwal D (2017) Oxime-modified aluminium(III) alkoxides: potential precursors for gamma-alumina nano-powders and optically transparent alumina film. Mater Res Bull 93:373-380

56. Belekar R, Dhoble S (2018) Activated alumina granules with nanoscale porosity for water defluoridation. Nan Struct Nano Object 16:322-328

57. Satya SS, Chandu BR, Ashis KM (2015) Formulation development and optimization of nanosuspension of simvastatin for improved solubility by nanomilling. J Pharm Sci Technol 5:78-87

58. Xu B, Wang L, Liu Y, Zhu H, Wang Q (2018) Preparation of high strength and transparent nanocomposite hydrogels using alumina nanoparticles as cross-linking agents. Mater Lett 228:104-107

59. Kiran T, Chintha S, Jithan A (2015) Formulation, optimization and evaluation of oral nanosuspension tablets of nebivolol hydrochloride for enhancement of dissoluton rate. Der Pharm Lett 7(3):71-84

60. Sandhya J, Pavani A, Raja RR (2014) Formulation and evaluation of nanosuspension of nisoldipine. Int J Pharm Sci Rev Res 24(1):177-181

\section{Publisher's Note}

Springer Nature remains neutral with regard to jurisdictional claims in published maps and institutional affiliations. 